\title{
Experimental analysis of lithium ion batteries for low earth orbit CubeSat applications
}

\author{
R.W. Cook ${ }^{1}$, L.G. Swan ${ }^{1}$ \\ ${ }^{1}$ Renewable Energy Storage Laboratory, Department of Mechanical Engineering, Dalhousie University, Halifax, Canada \\ Riley.cook@dal.ca, Lukas.swan@dal.ca
}

\begin{abstract}
Three groups of 18-65 cylindrical lithium-ion cells with different positive active materials (NCA - nickel cobalt aluminium, NMC - nickel manganese cobalt, LFP - lithium iron phosphate) and electrode designs (high power, high energy) were tested using an accelerated low earth orbit (LEO) CubeSat power profile cycle. Each design yields a unique energy density, power capability and cycle life. Each cell type was tested in a 3P group configuration at $10{ }^{\circ} \mathrm{C}$ under hard vacuum $(\sim 0.2 \mathrm{kPa})$ and atmospheric pressure $(\sim 101 \mathrm{kPa})$. Cells groups were operated in their respective ambient condition until they failed to successfully execute the accelerated LEO cycle. In atmospheric and vacuum pressure, both NMC groups failed due to internal resistance growth. The atmospheric pressure NCA group failed due to excessive internal gas build-up causing the CID (current interrupt device). The NCA group in vacuum pressure has completed approximately 2,680 orbits or 505 equivalent $100 \% \Delta \mathrm{SoC}$ cycles and is still operational showing $25 \%$ capacity degradation from its initial capacity. The LFP groups both in vacuum and atmospheric pressure have completed approximately 2,680 orbits or 1,730 equivalent $100 \% \Delta \mathrm{SoC}$ cycles and are still operational with both showing $13 \%$ capacity degradation from their initial capacity.
\end{abstract}

Keywords - Battery; Lithium ion; Degradation; Satellite; CubeSat; Nanosatellite

\section{INTRODUCTION}

\section{A. Background}

The space industry is increasingly adopting nano-satellites as a means of cost-effective services and exploration, with CubeSats $(10 \times 10 \times 10 \mathrm{~cm})$ being a popular nano-satellite class. The low cost of CubeSats ( $\$ 200,000$ to $\$ 2$ million) relative to conventional medium and larger satellites $(\$ 50$ million to $\$ 2$ billion) establishes a clear cost benefit of utilizing CubeSats [1], which has led to significant deployment growth on a global scale over the last 10 years [2]. Parallel to the growth of CubeSat technology, there has been tremendous development and production ramp of lithium-ion batteries (LIB). The first rechargeable LIB was made commercially available by Sony in 1991 and contained a LCO (lithium cobalt oxide) positive electrode material [3]. Since then, a range of other positive active materials (PAM) have been developed such as NCA (nickel cobalt aluminium), NMC (nickel manganese cobalt), and LFP (lithium iron phosphate). Each PAM variant offers trade-offs which include power capability, energy density, specific energy, cycle life and cost. At present, there is a gap in the literature regarding performance comparison of these PAM variants for LEO CubeSat applications which have unique cycling profiles at relatively low temperature.

\section{B. Literature Review}

In 2005, Wang [4] experimentally investigated the use of LCO chemistry for LEO space applications. They examined the effect of charge rate and voltage taper cut-off with respect to cell performance and impedance growth. At the time, LCO was the mass-produced lithium-ion chemistry. More recent work by Navarathinam et al. [5] investigates various LIB and lithium-polymer cells for CubeSat applications showing 25\% capacity degradation in standard temperature and pressure $(0$ ${ }^{\circ} \mathrm{C}, 101 \mathrm{kPa}$ ) after 700 orbits. However, Navarathinam et al. [5] did not repeat the 700 orbits in vacuum conditions to fully prove their cells ability in the LEO environment. Additionally Navarathinam et al. [5] did not differentiate the different LIB by their respective PAM. Work by Clark [6] and Jeevarajan [7]-[10] experimentally test the pouch cell formats for LEO small satellite applications with the intent to improve the energy density onboard a satellite by utilizing the pouch format as opposed to the cylindrical format. The motivation to validate pouch cells for LEO is driven by the $5-10 \%$ increase in specific energy $(\mathrm{Wh} / \mathrm{kg})$ the mylar wrapped pouch cell has compared to the steel cylindrical can cell. It should be noted that to date, no pouch cell can withstand the vacuum in LEO without the addition of external restraints that reduce overall specific energy. Although a $5-10 \%$ increase in battery specific energy is beneficial to CubeSats, it is of our belief that choosing the proper cell has the potential to minimize the required mass and volume of energy storage onboard a CubeSat by more than $5-10 \%$. 
Presently, CubeSat missions typically utilize commercial off the shelf lithium-ion batteries such as the 18-65 $(18 \mathrm{~mm}$ diameter and $65 \mathrm{~mm}$ height) Panasonic NCR18650B. CubeSat teams [11], [12] typically choose this cell based purely on its flight heritage. JPL [13] considers the Panasonic NCR18650B to be the current state of practice with future "State of the art" cells having a higher initial energy density. The strict mass and volume requirements of a $2 \mathrm{U}$ CubeSat mission typically only accommodates three to four 18-65 cells, hence, cells with the highest energy density provide the largest initial energy capacity for the CubeSat. An increase in initial energy capacity reduces the $\Delta \mathrm{SoE}$ (state of energy) and consequently the $\triangle \mathrm{SoC}$ required from the cell which is proven to increase cycle life and is why there is such a drive to utilize cells with high initial energy density such as Panasonic NCR18650B for CubeSat applications. However, high initial capacity is typically traded off for cyclability. The Panasonic NCR18650B has lower cycle life in comparison to a LFP cell such as the LithiumWerks APR18650M1B cell with a low initial capacity, high power rating and cyclability. Few CubeSats utilize the LFP chemistry in their design. Drieger's [14] conference paper discloses a $3 \mathrm{U}$ CubeSat design that uses the LFP cell chemistry, however this LFP design choice is presented without any engineering justification. Having a lower initial capacity requires the cell to operate at a larger $\Delta \mathrm{SoC}$ in order to perform the same task, which lowers its cyclability. However, if a low initial capacity cell can achieve a greater total discharge energy throughput regardless of its increase in $\Delta \mathrm{SoC}$, the questions remains whether a short life chemistry with high initial capacity provides the minimal battery mass and volume for a CubeSat. With CubeSat missions extending to 18 months or longer, there should be more emphasis placed on a cells cyclability as opposed to its initial capacity, energy density and specific energy to minimize the required mass and volume of a CubeSat battery storage system.

Choi [15], Crawford [16] and Omar [17] have investigated LIB PAM variants for a variety of other applications, notably for peak shaving, frequency regulation, and electric vehicle services. Findings include:

- LFP and NCA have similar degradation rates in electricity grid frequency regulation applications [15], [16].

- LFP has the lowest IR (internal resistance) growth under all applications compared to NCA [16].

- LFP has high power and capability at low temperature compared to NCA and NMC chemistry for electricity grid peak shaving, frequency regulation and electric vehicle applications [17].

The findings by Choi [15], Crawford [16] and Omar [17] raise the question as to what chemistry would be ideal for CubeSat applications which have high cycling requirements and relatively low temperature operation.

\section{METHOD}

\section{A. Experimental Setup}

Three LIB 18-65 cylindrical cell groups, were tested in ambient pressure $(\sim 101 \mathrm{kPa})$ and vacuum $(\sim 0.2 \mathrm{kPa})$ at $10^{\circ} \mathrm{C}$. The vacuum present in LEO is approximately $10^{-6} \mathrm{~Pa}$ [18], the lowest vacuum obtainable with our vacuum chamber and pump apparatus is $200 \mathrm{~Pa}$ which achieves $99.8 \%$ of the vacuum in LEO. A $10{ }^{\circ} \mathrm{C}$ environment coincides well with the observed average temperature in LEO presented by Harvey and Kinard [19]. The cells were subject to a representative LEO power cycle consisting of constant power discharge, and sinusoidal power charge, with reference cycles completed at $25{ }^{\circ} \mathrm{C}$ after every 480 orbits to obtain capacity and internal resistance measurements.

\section{B. Lithium-ion Cells}

The cells used in this study were the Panasonic NCR18650B (NCA), LG Chem ICR18650B4 (NMC) and A123/LithiumWerks APR18650M1B (LFP). Each cell type has a unique PAM and electrode size (length, thickness), but are packaged in the same 18-65 cylindrical format. The cell types range significantly in design, see Table 1.

Table 1: Panasonic (NCA), LG Chem (NMC) and LithiumWerks (LFP) Specification Sheet Data

\begin{tabular}{rccc}
\hline PAM Chemistry & NCA & NMC & LFP \\
\hline Capacity (Ah) & 3.35 & 2.6 & 1.1 \\
\hline Nominal (V) & 3.6 & 3.6 & 3.3 \\
\hline Max cont. discharge power (W) & 24 & 19 & 100 \\
\hline $\mathbf{8 0 \%}$ Cycle Life & 250 & 300 & 2000 \\
\hline
\end{tabular}

A cell from each type was dissected and SEM (scanning electron microscopy) imaged, see Figure 1.

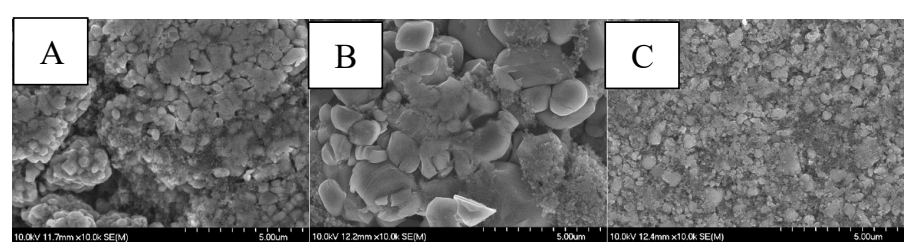

Figure 1: PAM SEM Image (A: NCA, B: NMC, C: LFP), 10.0 kV, x10,000 magnification

EDS (energy dispersive spectroscopy) analysis was performed on the PAM and NAM (negative active material) of each cell in order to confirm the active materials. Using EDS, the PAM of the NCA, NMC and LFP cells were respectively found to be $\mathrm{LiNi}_{0.83} \mathrm{Co}_{0.14} \mathrm{Al}_{0.3} \mathrm{O}_{2}, \mathrm{LiNi}_{0.5} \mathrm{Mn}_{0.3} \mathrm{Al}_{0.2} \mathrm{O}_{2}$ and $\mathrm{LiFePO}_{4}$.

\section{Accelerated Cubesat Low Earth Orbit Cycles}

One normal LEO typically takes 90 minutes, resulting in 16 orbits per 24-hour period (earth day). Orbit time varies with altitude and orbit velocity with a maximum eclipse time of 35 minutes [20], [21]. During this 35-minute (2,100 second) 
eclipse, the battery is discharged with a remaining 55-minute (3,300 second) charge period. In order to expedite cycling in, the low earth orbit cycle was accelerated by a factor of 3 , with 700 second discharge periods and 1,100 second charge periods for a total orbit period of 30 minutes. During the eclipse simulation a constant power of 33.6 watts is discharged for 700 seconds from a 3P cell group, resulting in 2.178 Watthours discharged per cell. During insolation, charge follows a sinusoidal profile to represent a solar orbit with fixed photovoltaic orientation, and sufficient energy will be delivered to support a cell of $74 \%$ energy efficiency or greater. But since most LIB cells are well above a $74 \%$ energy efficiency, they terminate charge early. The discharge-charge profile is shown in Figure 2.

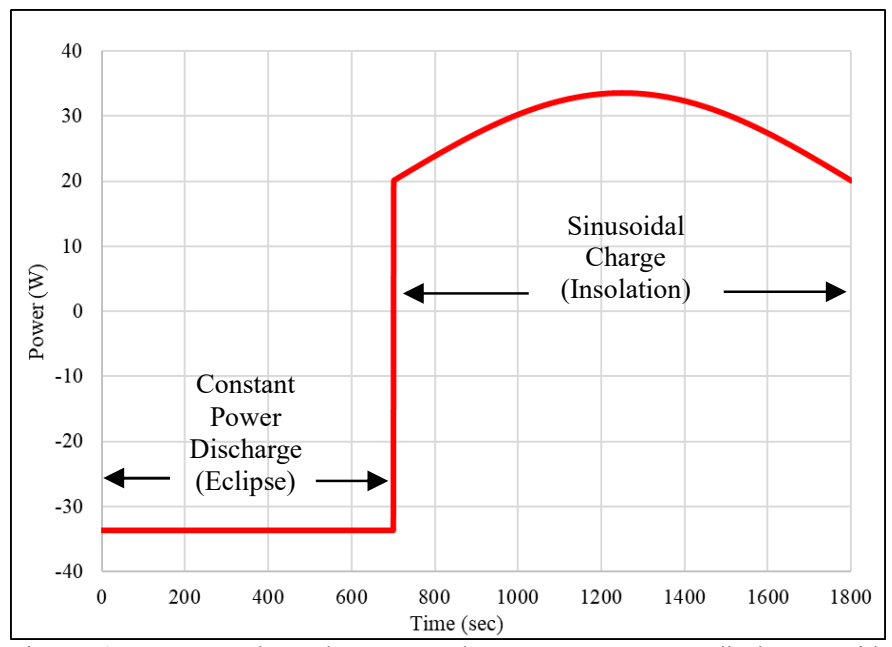

Figure 2: One accelerated LEO cycle. Constant power discharge with sinusoidal charge profile

During LEO cycling, T-type thermocouples were adhered to the middle cell of the $3 \mathrm{P}$ group, the inside of the vacuum chamber, and the thermal chamber for recording and safety purposes. Lithium-ion cells experience capacity degradation during cycling, therefore, cell groups in orbit are always cycled at partial $\Delta \mathrm{SoC}$ to leave an allowance for degradation. Maximizing the $\triangle \mathrm{SoC}$ during cycling will increase the rate of degradation and is ideal for expediting the experiment. During the eclipse portion of orbit, a constant power discharge of 33.6 watts was used to obtain a $60 \% \Delta$ SoC from the 3 P LFP cell group configuration. Because the other cell groups are greater capacity, this equals $18 \%$ and $23 \% \Delta \mathrm{SoC}$ from the NCA and NMC cell groups, respectively. Prior to the first orbit, $10 \%$ of each cell groups capacity is discharged in order to not operate cells near the fully charged condition.

\section{Reference Cycles}

Reference cycles were completed on single cells as opposed to the $3 \mathrm{P}$ configuration used in accelerated LEO cycling. Reference cycles were completed at $25^{\circ} \mathrm{C}$ as this is the ideal operating temperature for each cell type and the temperature given in the specification sheet [22]-[24]. To achieve a capacity measurement on each cell between orbits, three $100 \%$ full charge ( 2 hour rate) and discharges (1 hour rate) were completed with the third cycle discharge capacity used to represent the remaining capacity in the cell. During reference cycling, each cell has a T-type thermocouple adhered to its side.

Direct current IR reference cycles were completed during 1 full charge and discharge cycle using 30 second pulses that doubled the respective charge and discharge current.

\section{E. Equipment}

A Neware BTS 5V50A [25] power cycler was used to complete all cycling. All cells were cycled in a CSZ-32 [26] thermal chamber at $10{ }^{\circ} \mathrm{C}$ during accelerated orbit and $25^{\circ} \mathrm{C}$ for all reference cycles. The experimental setup is shown in Figure 3 and Figure 4.

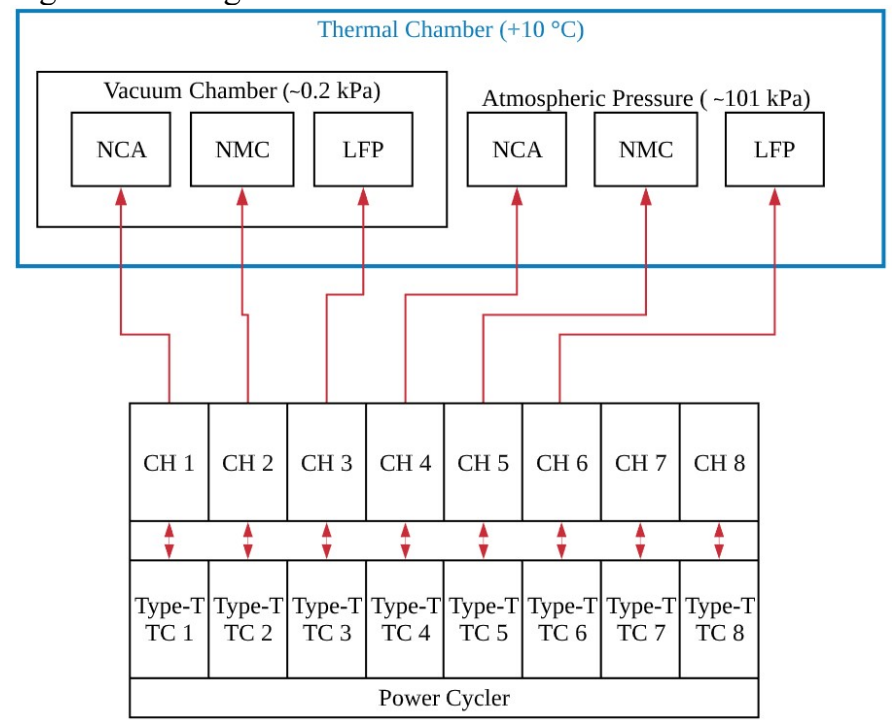

Figure 3: Experimental setup layout: $\mathrm{CH}$ (Channel), TC (thermocouple)

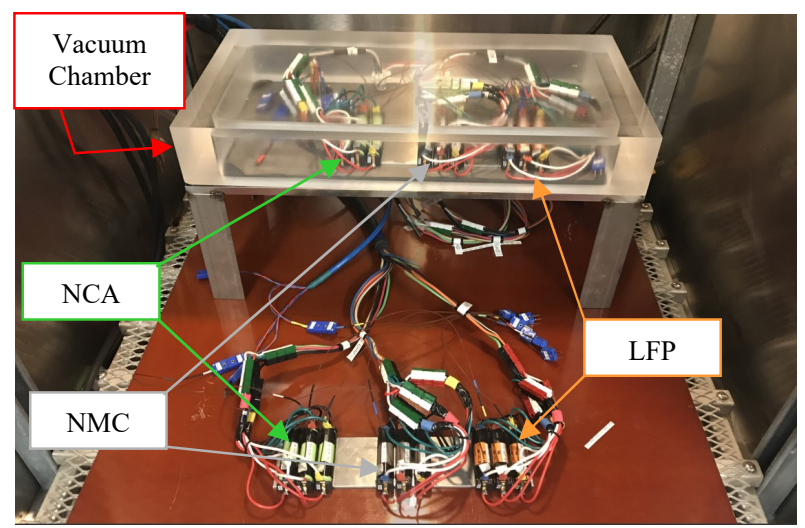

Figure 4: Experimental setup in thermal chamber $\left(10^{\circ} \mathrm{C}\right)$ showing vacuum chamber $(\sim 0.2 \mathrm{kPa})$ and atmospheric $(101 \mathrm{kPa})$ test cells in 3P groupings.

\section{RESULTS}

The energy and coulombic capacity degradation curves are plotted against orbits, energy throughput and equivalent $100 \%$ $\Delta \mathrm{SoC}$ cycles. The thermal response of cells in reference cycle conditions, vacuum $(\sim 0.2 \mathrm{kPa})$ and atmospheric $(\sim 101 \mathrm{kPa})$ are presented and related to internal resistance and energy 
efficiency measurements. Data points marked with a cross ' $X$ ' indicate the point in which the cell group failed during orbit. Absence of an ' $\mathrm{X}$ ' indicates the cells are still operational at the time of writing this paper. Range bars are added to each data point to represent the minimum and maximum cell with respect to the median cell for each $3 \mathrm{P}$ cell group. Each data point was obtained from a reference cycle.

\section{A. Energy \& Coulombic Capacity Degredation}

The median cell discharge energy is plotted for each cell group with respect to its completed orbits and energy throughput in Figure 5 .

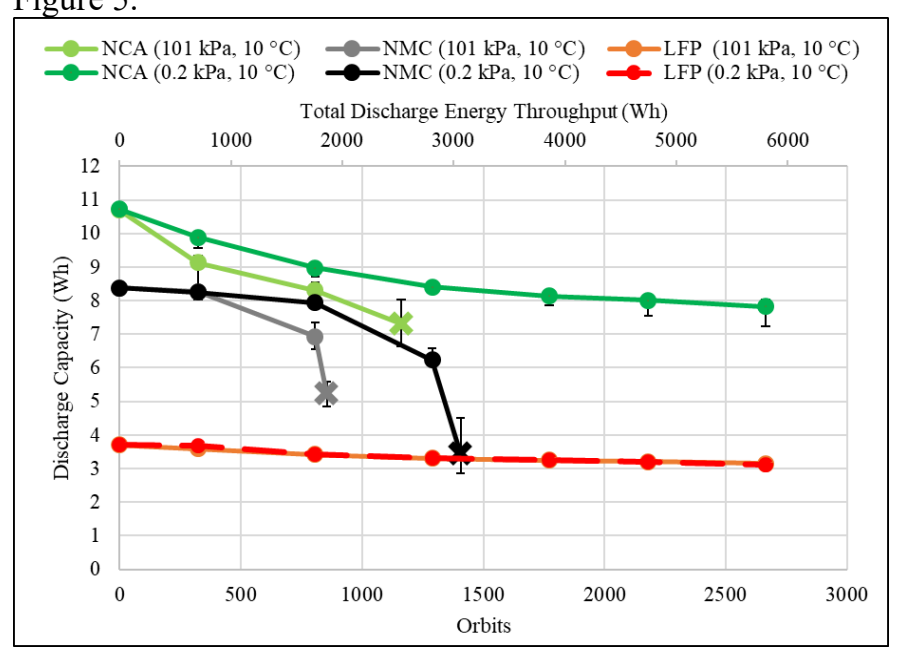

Figure 5: Cell discharge capacity vs. completed orbits and energy throughput of cells from each chemistry (NCA, NMC \& LFP) and pressure condition $(0.2$ $\mathrm{kPa} \& 101 \mathrm{kPa})$.

The span between data points is 480 accelerated low earth orbit cycles. Figure 5 shows that both NCA and NMC cells experienced increased degradation rates in atmospheric pressure compared to vacuum. Figure 6 represents the data as a function of equivalent $100 \% \Delta \mathrm{SoC}$ cycles.

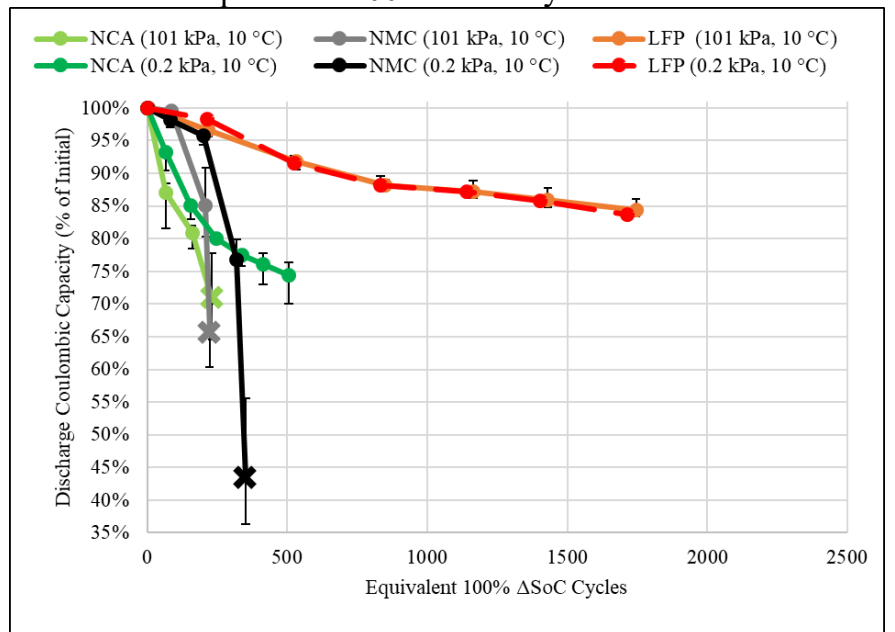

Figure 6: Median cell remaining capacity vs. equivalent $100 \% \Delta \mathrm{SoC}$ cycles of cells from each chemistry (NCA, NMC \& LFP) and pressure condition $(0.2$ $\mathrm{kPa} \& 101 \mathrm{kPa})$
The NCA cells in both pressure conditions show continued capacity decline. There is an immediate decrease in capacity for NCA cells in atmospheric and vacuum conditions. The NMC cells in both conditions show little initial capacity decline, however there is a sudden significant decrease in capacity after the second and third reference points for the atmospheric and vacuum condition respectively, both eventually resulting in cell group failure. In both conditions, the LFP cell groups show little capacity degradation relative to the NCA and NMC cells. Figure 6 highlights the high cyclic ability of the LFP relative to the NCA and NMC cell groups. Initially, the degradation rate of both NCA groups is much higher than the NMC and LFP groups; reaching $80 \%$ of initial capacity at 160 cycles (atmospheric) and 250 cycles (vacuum). The vacuum NCA group operates at $22{ }^{\circ} \mathrm{C}$ and its capacity degradation rate agrees well with the provided data sheet degradation at $25{ }^{\circ} \mathrm{C}$. The difference between the NCA group in atmospheric and vacuum is attributed to the lower median cell operating temperature of the atmospheric cells $\left(16{ }^{\circ} \mathrm{C}\right.$ average) vs. vacuum $\left(22^{\circ} \mathrm{C}\right.$ average). Initially the $\mathrm{NMC}$ groups experience slower degradation rates than NCA. The NMC degradation rate begins to exceed that of the NCA after 210 (atmospheric) and 300 (vacuum) equivalent $100 \% \quad \Delta \mathrm{SoC}$ cycles. This occurrence can be explained by the exponential internal resistance growth occurring in the NMC cells at 210 and 300 equivalent $100 \% \Delta \mathrm{SoC}$ cycles whereas the internal resistance growth in the NCA cells starts to plateau.

\section{B. Internal Resistance and Energy Efficiency}

The minimum internal resistance for each cell group under both vacuum and atmospheric are shown in Figure 7.

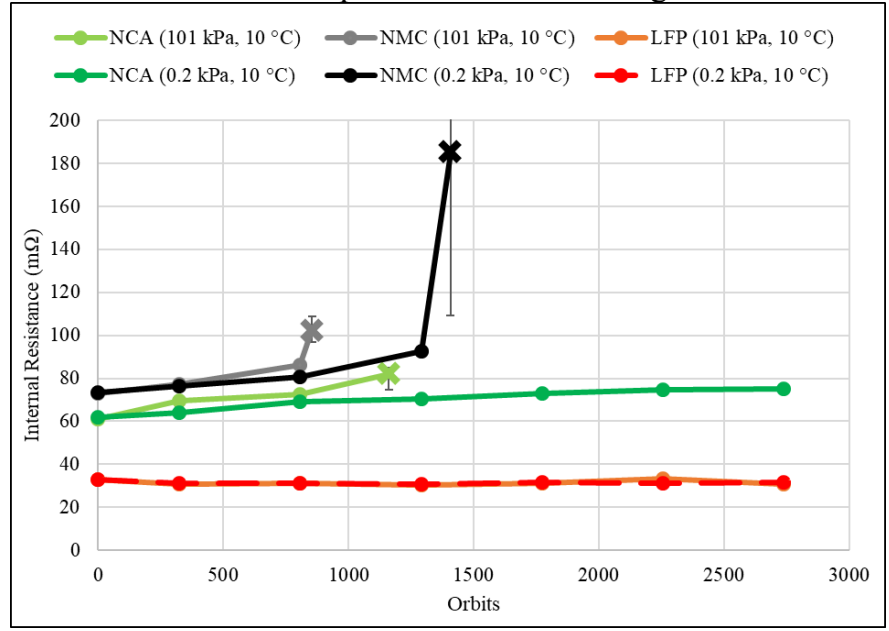

Figure 7: Internal resistance measured during charge/discharge reference pulses of cells from each chemistry (NCA, NMC \& LFP) and pressure condition $(0.2 \mathrm{kPa} \& 101 \mathrm{kPa})$

Figure 7 shows the continuous internal resistance growth for both NCA and NMC groups in atmospheric and vacuum. The internal resistance growth is greater in ambient pressure due to the lower operating temperature. The atmospheric pressure NMC group experiences a sharp increase in internal resistance immediately prior to failure at orbit 854 . These sharp increases in internal resistance in both NMC groups caused the groups 
to fail. LFP experiences no discernable internal resistance growth in the first 2,680 orbits. The NCA cell shows a continuous internal resistance growth which has started to plateau after approximately 2000 orbits. Although the NCA group in atmospheric pressure started to experience internal resistance growth prior to failure, its final cause of failure was due to two cells in the group generating internal gas causing the CID to electrically disconnect the cell internally. The changes in internal resistance are reflected in each groups energy efficiency as shown by Figure 8 .

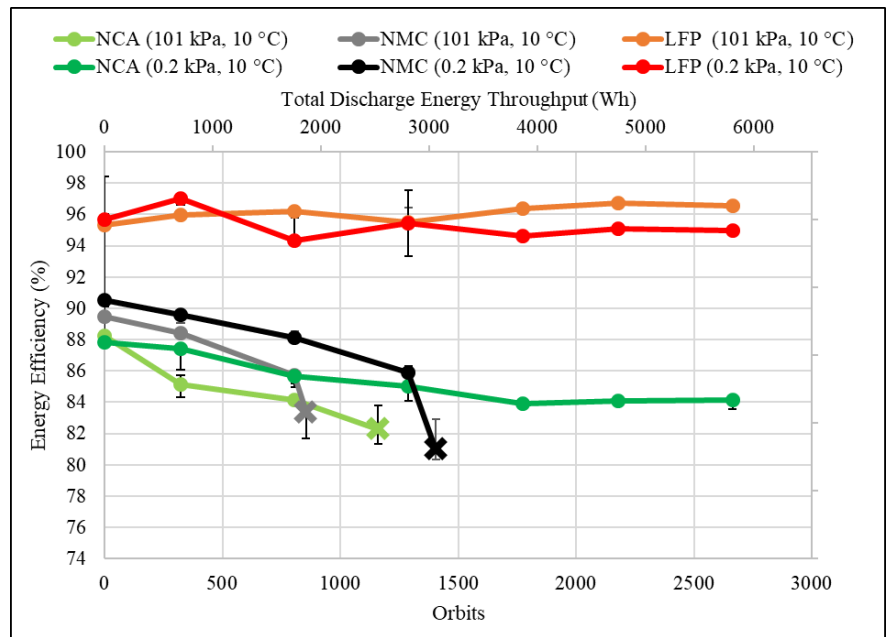

Figure 8: Energy efficiency vs. orbits of cells from each chemistry (NCA, NMC \& LFP) and pressure condition ( $0.2 \mathrm{kPa} \& 101 \mathrm{kPa})$

\section{Thermal Response}

The thermal response of a cell is dependent on its energy efficiency and the load applied to the cell. The inefficiency of a cell is inversely related to its internal resistance. The thermal profile during a reference cycle correlates well with each cell's internal resistance throughout the discharge-charge cycle as shown in Figure 9.

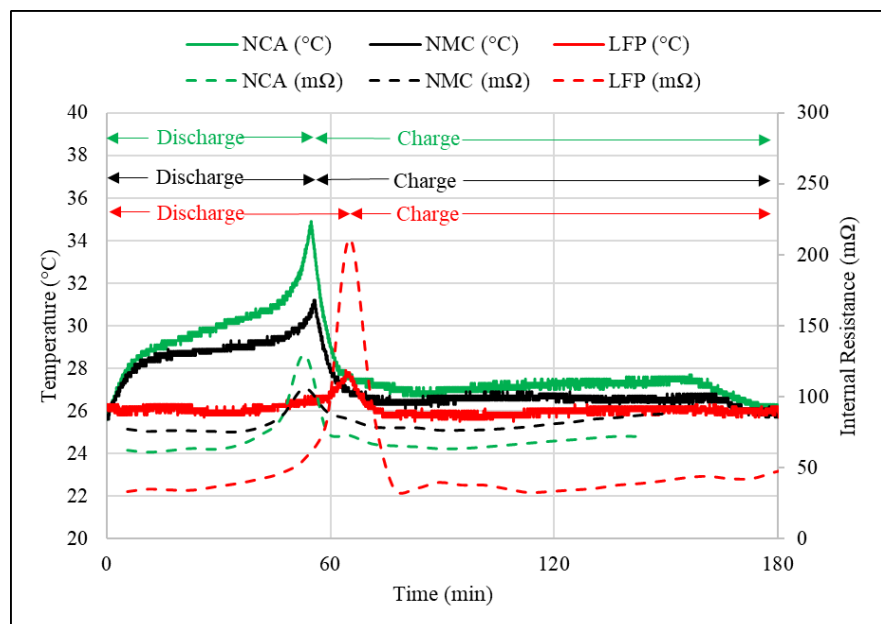

Figure 9: Thermal profile and internal resistance of each chemistry (NCA, NMC \& LFP) during $1^{\text {st }}$ reference cycle. Solid lines $\left({ }^{\circ} \mathrm{C}\right)$, dashed lines $(\mathrm{m} \Omega)$.
Thermal Profile: Discharge (1 C), Charge (C/2). Internal resistance from 30 second pulses: Discharge pulse (2 C) Charge pulse (1 C).

The NCA cell operates at the highest temperature with the greatest temperature peak. The NMC cell's temperature peak is slightly less than the NCA cell and the LFP cell operates significantly cooler than the NCA and NMC. The internal resistance plot of both NCA and NMC cells end early due to the charge and discharge cut-off voltage limits being reached prematurely during pulse measurements required to obtain internal resistance measurements. Each cell's peak internal resistance occurs at the end of discharge and correlates with the peak temperature achieved. As each cell has a different capacity and was cycled at the same rates, the magnitude of the internal resistance peak does not correlate to the magnitude of the thermal response. Reference cycles are completed at $101 \mathrm{kPa}$ and $25{ }^{\circ} \mathrm{C}$ which occur every 480 orbits, thus the majority of cycling (greater than $99 \%$ ) is completed under the accelerated LEO cycle in vacuum $\left(0.2 \mathrm{kPa}, 10{ }^{\circ} \mathrm{C}\right)$ and atmospheric $\left(101 \mathrm{kPa}, 10{ }^{\circ} \mathrm{C}\right)$. The convective heat transfer properties in atmospheric and vacuum pressure differ substantially. This was well quantified by Saidi [27] showing that a decrease in pressure caused a decrease in the convective heat transfer coefficient. The various convective properties result in different temperature profiles directly affecting cell performance. Higher cell temperatures result in a lower internal resistance. The increased degradation rate under atmospheric pressure is due to the greater convective heat transfer coefficient keeping the cells cooler (closer to $10{ }^{\circ} \mathrm{C}$ ) than the cells operating in the vacuum condition. Cells in vacuum achieved near optimal operating temperature $\left(25^{\circ} \mathrm{C}\right)$ while cells in atmospheric pressure operated 5 to $10^{\circ} \mathrm{C}$ cooler than their vacuum condition counterpart. The temperature profile for cells operating inside vacuum and atmospheric pressure are shown in Figure 10 for the $10^{\text {th }}$ orbit completed.

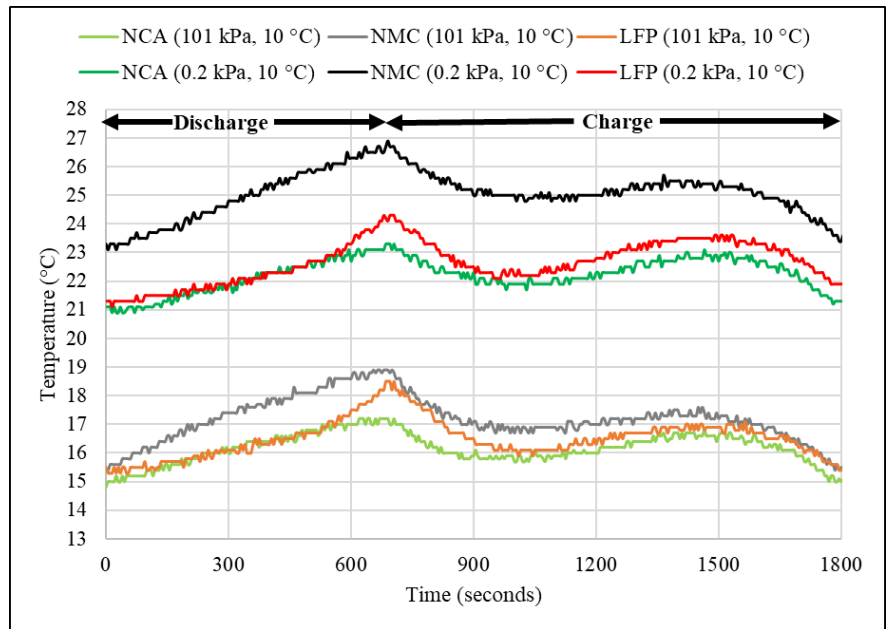

Figure 10: Thermal profile of each chemistry (NCA, NMC \& LFP) during $10^{\text {th }}$ orbit in both vacuum $\left(0.2 \mathrm{kPa}, 10^{\circ} \mathrm{C}\right)$ and atmospheric $\left(101 \mathrm{kPa}, 10^{\circ} \mathrm{C}\right)$

The $10^{\text {th }}$ orbit is shown as it takes 10 orbits for cells to reach their stabilized operating temperature. The temperature 
profiles in atmospheric pressure are similar, however, in vacuum the NMC cell group appear to operate $2{ }^{\circ} \mathrm{C}$ warmer than the NCA and LFP cell groups. By contrasting Figure 9 and Figure 10 it's clear that the warmest cell during orbit is not the warmest during reference cycling.

\section{CONCLUSION}

Three cell types from different manufacturers were cycled in $3 \mathrm{P}$ groups in vacuum $(\sim 0.2 \mathrm{kPa})$ and atmospheric $(\sim 101 \mathrm{kPa})$ conditions at $10{ }^{\circ} \mathrm{C}$. Cells operating in vacuum achieved higher operating temperatures than those in atmospheric pressure. The higher operating temperature in vacuum decreased the observed capacity degradation in the NCA and $\mathrm{NMC}$ groups. The NMC group in atmospheric pressure failed from continuous internal resistance growth. The NCA group in ambient pressure failed due to two of the three cells producing excessive internal gas causing their CID to electrically disconnect. In the atmospheric pressure condition, the LFP group outperformed the NCA and NMC groups with respect to degradation rates, internal resistance growth and operational status. The atmospheric LFP group shows negligible difference in capacity degradation and internal resistance growth compared to its vacuum condition counterpart. Remaining cells in operation include both LFP groups $(0.2$ $\mathrm{kPa} \& 101 \mathrm{kPa})$ and the NCA group $(0.2 \mathrm{kPa})$. Although cells are identified by their PAM, cell failure may be a result of failure mechanisms such as lithium plating at the negative electrode. Future work will be dedicated to analysing the elements of each cell groups failure mechanisms.

\section{ACKNOWLEDGMENTS}

We thank the Canadian Space Agency for funding this research project through a grant awarded to Kevin Plucknett et al.

\section{REFERENCES}

[1] S. Gao et al., "Antennas for modern small satellites," IEEE Antennas Propag. Mag., vol. 51, no. 4, pp. 40-56, 2009.

[2] Nanosats, "NanoSatellite Database." [Online]. Available: https://www.nanosats.eu/\%0A. [Accessed: 03-Mar-2019].

[3] G. M. E. J.R. Dahn, "Chapter 17: Lithium-Ion Batteries," pp. 1-131.

[4] X. Wang, Y. Sone, and S. Kuwajima, "Effect of operation conditions on simulated low-earth orbit cycle-life testing of commercial lithium-ion polymer cells," J. Power Sources, vol. 142, no. 1-2, pp. 313-322, 2005.

[5] N. Navarathinam, R. Lee, and H. Chesser, "Characterization of Lithium-Polymer batteries for CubeSat applications," Acta Astronaut., vol. 68, no. 11-12, pp. 1752-1760, 2011.

[6] C. S. Clark and E. Simon, "Evaluation of Lithium Polymer Technology for Small Satellite Applications," 21st Annu. AIAA/USU Conf. Small Satell., no. August, pp. 1-11, 2007.

[7] J. Jeevarajan, D. Ph, J. Jeevarajan, and P. D. Nasa-jsc, "Tolerance of Li-ion Pouch Cells to Varied Space Environment Pressures Lithium Power 2012," 2012.

[8] J. A. Jeevarajan and T. Inoue, "A Novel Lithium-ion Laminated
Pouch Cell Tested For Performance And Safety," no. 281, pp. 2-5, 2000.

[9] J. Jeevarajan, "Safety and Long-Term Performance of Lithium- ion Pouch Cells," 2017.

[10] J. A. Jeevarajan and B. E. Duffield, "Performance and Safety of Lithium-Ion Polymer Pouch Cells," J. Sp. Saf. Eng., vol. 1, no. 1, pp. 10-16, 2014.

[11] QMSat Team, "Preliminary Design Review QMSat Team Mission objective of QMSat," in CSA-CCP-PDA-0002, 2019, pp. 1-111.

[12] U. of N. B. New Brunswick Community College, University de Moncton, "Preliminary Design Review CubeSat NB Team New Brunswick Community College Université de Moncton University of New Brunswick CCP-CNB-00040-COM-RP-P2 Mission Overview \& Payload," in CCP-CNB-00040-COM-RP-P2, 2019.

[13] D. Muthulingam, "Power Subsystem Options for CubeSat OpComm," pp. 1-12.

[14] M. Driedger, M. Taverner, and V. Platero, "SSC18-PI-23 TSAT4 : A Modular 3U CubeSat Characterizing Anabaena Cylindrica in Low Earth Orbit."

[15] D. Choi, A. Crawford, Q. Huang, V. V Viswanathan, M. C. KintnerMeyer, and V. L. Sprenkle, "Lifecycle Evaluation of Li-ion Battery Chemistries under Grid Duty Cycles,” pp. 1-15, 2016.

[16] A. J. Crawford et al., "Lifecycle comparison of selected Li-ion battery chemistries under grid and electric vehicle duty cycle combinations," J. Power Sources, vol. 380, no. December 2017, pp. 185-193, 2018.

[17] N. Omar et al., "Assessment of performance of lithium iron phosphate oxide, nickel manganese cobalt oxide and nickel cobalt aluminum oxide based cells for using in plug-in battery electric vehicle applications," 2011 IEEE Veh. Power Propuls. Conf. VPPC 2011, pp. 1-7, 2011.

[18] NASA, US Standard Atmosphere, 1976. 2019.

[19] G. A. Harvey and W. H. Kinard, "MISSE $1 \& 2$ Tray Temperature Measurements e MISSE Post-Retrieval Conference," no. June, 2006.

[20] K. K. de Groh, B. A. Banks, and D. C. Smith, "Environmental durability issues for solar power systems in low earth orbit," p. 14, 1995.

[21] Yannick Borthomieu, Satellite Lithium-Ion Batteries Chapter 14 Yannick Borthomieu.pdf. .

[22] Panasonic, "Panasonic NCR18650B Data Sheet.".

[23] J. J. Kim and S. H. Ahn, "LG Chem ICR18650B4 Data Sheet," vol. 21, no. 1. 2011.

[24] LithiumWerks, "LithiumWerks APR18650M1B Data Sheet." pp. 12.

[25] Neware, "Neware BTS-5V50A (8Ch) Technical Specification Document," no. 128, 2018.

[26] I. Cincinnati Sub-Zero Products, "CSZ-Z series thermal chamberoperator manual 56276 REV F.pdf.”.

[27] M. Saidi and R. H. Abardeh, "Air pressure dependence of naturalconvection heat transfer," WCE 2010 - World Congr. Eng. 2010, vol. 2, pp. 1444-1447, 2010. 